\title{
Development of Physical Properties of Apple during Dehydration
}

\author{
Rym Mbarek ${ }^{1,2}$, Daoued Mihoubi2* \\ ${ }^{1}$ Higher School of Food Industries of Tunis, 58 Av. Alain Savary, 1003 Tunis El Khadra City, Tunisia \\ ${ }^{2}$ Laboratory of Wind Energy Management and Waste Energy Recovery, Research and Technology Center of Energy (CRTEn), \\ B.P. No. 95, Hammam-Lif 2050, Tunisia \\ * Corresponding author, e-mail: daoued.mihoubi@crten.rnrt.tn
}

Received: 24 August 2018, Accepted: 13 November 2018, Published online: 16 April 2019

\begin{abstract}
The evolution of physical properties (shrinkage, density and porosity) of cylindrical shaped apple samples (Golden Delicious) during convective drying was investigated. For this purpose, the weight and the dimensions (diameter, height) of apple samples were monitoring at regular time intervals of the drying process. A constant drying rate period was not detected although considering the reduction of the exchange surface area. Apple exhibited a clear anisotropy behavior of the shrinkage coefficients. The volume shrinkage of apple samples showed a linear relationship with moisture content $\left(R^{2}=0.996\right)$. A theoretical relation between the surface ratio and the volume ratio was determined $\left(R^{2}=0.956\right)$. During drying process, the apparent density of apples decreased with decrease in moisture content following a second-degree polynomial curve $\left(R^{2}=0.991\right)$, whereas the true density aggrandized with removal of water. The porosity of apple samples was showed to increase as drying progressed. At the starting of the drying process, the porosity changes resulted from the reduction of the total volume. Then, the porosity changes during drying were found to be a consequence of a loss of water and a simultaneous reduction of gaseous volume.
\end{abstract}

\section{Keywords}

apple, drying, shrinkage, density, porosity

\section{Introduction}

During the drying of foods classified as highly deformable materials, there is a balance between volume reduction, density of non-gaseous components and porosity. So that, monitoring the evolution of these properties during the drying process has been considered as a valuable tool to evaluate the relationships between shrinkage, density and porosity, to understand the drying behavior of a food material and to obtain basic data required for mathematical modelling and simulation of the drying process. Moreover, the physical properties of a material are important criteria revealing the quality of a dry product.

The reduction of the volume of a foodstuff with loss of water during drying is expressed as shrinkage. The fold of capillaries during drying was the principal cause of this fact [1]. Pakowski and Adamski [2] proved experimentally that the shrinkage of apple tissue during convective drying could be explained by the stresses resulting from the development of a negative internal pressure of $-90 \mathrm{kPa}$ in the solid phase. The apple volume reduction during drying depends on the drying method [1]. According to Ratti [3], the increase in air velocity decreased the volume shrinkage of potatoes. This effect was less pronounced in apples and negligible in carrots. The others drying variables; relative humidity of air (5-50\%), temperature $\left(40-60^{\circ} \mathrm{C}\right)$ and sample geometry (disks or cylinders) had a negligible effect on the volume shrinkage of these products within the range of conditions studied. It was reported also that the method of averaging a number of measurements of sample dimensions was suitable for the calculation of the sample volume within the entire range of moisture contents.

Shrinkage of dried food affects significantly their density [4]. Witrowa-Rajchert and Rząca [1] observed a similar trend in the density of dried apple in comparison to the shrinkage. Krokida et al. [5] reported that the apparent density of apple was significantly affected by the drying method (conventional drying, vacuum drying, microwaves, osmotic dehydration and freeze drying). The freeze dried apples were characterized by the lowest apparent density values, 
while the microwave dried and conventionally dried apples were characterized by the highest apparent density values. It has been also observed that, irrespective of the drying method used, the apparent density of apple decreased with decrease in moisture content. In the case of garlic [6], potato and carrot [7], the apparent density values were found to increase with the removal of water during drying.

During the drying process of a foodstuff, the shrinkage and density changes have a significant impact on its porosity. The evolution of this physical property during drying, depends on the initial moisture content, the composition, the size of the material in addition to the method and conditions of drying [8]. The porosity of a material may affect the diffusion coefficient, the rehydration rate and the final moisture content after rehydration, adsorption or absorption [5]. Krokidaet et al. [5], Zogzas et al. [7], Witrowa-Rajchert and Rząca [1] observed a noticeable increase in apple porosity during drying. On the contrary, almost fruits and vegetables developed low porosity values during drying such as garlic [6], carrots and potatoes [7], banana, pineapple and mango [9]. The porosity of apple depends strongly on the drying method used. The freeze dried apples developed the highest porosity values $(90 \%)$, while osmotically treated apples developed the lowest porosity values (50\%) [5]. Using some experimental parameters (densities, shrinkage curves, ...), Madiouli et al. [10] determined a method allowing to establish the bulk porosity changes of foodstuffs at different drying conditions and methods. Singh et al. [11] determined a mathematical model permitting to investigate the porosity behavior during drying of apple and potato, in function of the initial porosity and the pressure developed as a result of cells contractions during the mass transfer. For both products, the porosity changes revealed being strongly depended on the initial porosity of samples and the generated pressure for different studied drying methods. Wang and Martynenko [12] present some approaches permitting to estimate separately the total, open-pore and close-pore porosities of apple samples during convective drying. They reported that at moisture contents above the critical moisture content, there is no difference between total and open-pore porosities. Below the critical moisture content, the open-pore porosity sharply decreases while the close-pore porosity increases significantly as a result of glass transition phenomenon and hardening.

Qiu et al. [13] reviewed numerous methods used to measure and calculate physical properties (volume, bulk density and porosity) of food materials. They also evaluated their effectiveness and accuracy. Witrowa-Rajchert and
Rząca [1] compared the effect of three drying methods (convection, microwave-convection, infrared-convection) on the microstructure and the physical properties of dried apples (var. Idared). They reported that the convectively dried apples had the smallest volume (3.8 times lower than the initial volume), the largest shrinkage (about $74 \%$ ), the highest density $\left(4.410^{-10} \pm 0.310^{-10} \mathrm{~kg} / \mathrm{m}^{3}\right)$ and the lowest porosity $(71 \%)$. Whereas the apples dried by combined methods had lower volume of 30-34 \%, lower shrinkage of $11-12 \%$, lower density of $18-23 \%$ and higher porosity of 25-28\% than convectively dried ones. Joardder et al. [14] investigated the relationships between the characteristics of the cell walls of apple tissues (Granny Smith and Red delicious varieties) and the physical properties (shrinkage and porosity) of dried samples. They observed that the drying rates, physical attributes and microstructure were strongly affected by the cell walls properties of apple tissues.

To our knowledge, there is no detailed work, in the literature, that aimed to study experimentally and mathematically the evolution of different physical properties (longitudinal and radial shrinkage coefficients, volume and surface shrinkage, apparent and true densities, and porosity) during drying of cylindrical shaped apple samples (Golden Delicious) using the measured weights and the dimensions (diameter and height) determined with the aid of a digital microscope. Such study will be of great interest to obtain valuable data for simulation and modelling of the drying process.

The purposes of the current study were to:

1. study the shrinkage behavior of apples (Golden Delicious) during air drying;

2. determine the variation of the physical properties of apples (volume and surface shrinkage, apparent and true densities, and porosity) during drying; and

3. evaluate the relationships of these properties with variation of moisture content of apples.

\section{Materials and methods}

\subsection{Sample preparation}

Fresh apples from Golden Delicious variety were purchased from a local market in Nabeul, Tunisia. They were stored in the refrigerator at $+4{ }^{\circ} \mathrm{C}$ until use. Prior to starting the experiment, an apple was taken out from the refrigerator and washed. When its temperature reached the room temperature, it was peeled and its core was removed. Using a manual tool, three cylindrical samples were cut so that the axis of each sample was parallel to the main axis of the apple (the samples had the same orientation). The cylindrical 
shaped apple samples prepared had an average weight of $2.43 \mathrm{~g}$, an average diameter of $19.04 \pm 0.196 \mathrm{~mm}$ and an average height of $11.5 \pm 0.823 \mathrm{~mm}$. Average initial moisture content was found to be $87.45 \%$ (wet basis).

\subsection{Experimental procedure}

The experimental equipment used for drying of apple samples and monitoring the variation of their weights and dimensions (diameter, height) at regular time intervals during drying, is constituted by the following components: an adjustable electrically heated oven, equipped with a forced convection system through a fan allowing better heating and drying conditions, better uniformity of temperature and less fluctuation:

- an electronic balance of precision (KERN 770, Max: 220 g, Min: $0.01 \mathrm{~g}, d=0.0001 \mathrm{~g}, e=0.001 \mathrm{~g}$ ) for weighing of the apple samples,

- a digital microscope (HD Color CMOS Sensor, Optimal Resolution $640 \times 480,5 \times$ Digital zoom) connected to a computer through a "Cooling Tech" software which permit to capture pictures of the studied apple sample through the "CamApp" application, and to determine its dimensions (diameter, height).

Three cylindrical shaped apple samples were put on supports placed in the middle of the oven in front of the fan. The temperature of the drying chamber was maintained at $50{ }^{\circ} \mathrm{C}$. For drying time intervals of $15 \mathrm{~min}$, the apple samples were successively removed from the oven to weight them and to capture two pictures for every sample according to two different directions (radial and longitudinal). The capture of pictures must take place at the same position of the sample during the experiment. All measurements were performed rapidly so as not to disturb the drying operation. The drying of apple samples was carried out until reaching constant weights. At the end of the experiment, samples were placed in the oven at $105^{\circ} \mathrm{C}$ for about $24 \mathrm{~h}$ to obtain their dry weights. The experiment was repeated three times and the average values were used to plot the different curves.

\subsection{Data analysis}

\subsubsection{Mass flux}

As the exchange surface area of the apple sample tends to decrease substantially during drying due to shrinkage phenomena, a plot of mass flux as a function of moisture content would be more suitable for analyzing the drying behavior of apple than the drying rate curve as a function of moisture content. The mass flux $\left(q_{v}\right)$ is defined as the mass loss per unit of time and area:

$q_{v}=-\frac{d X}{d t} \times \frac{m_{s}}{A}$

where $X$ is the moisture content per unit mass of solids ( $\mathrm{kg} / \mathrm{kg}$ d.m.), $m_{s}$ is the dry mass $(\mathrm{kg})$ and $A$ is the exchange surface area $\left(\mathrm{m}^{2}\right)$.

The exchange surface area $(A)$ was calculated from the measured diameter $(d)$ and height $(\lambda)$ of the cylindrical shaped apple sample. Eq. (1) assumes that the cylindrical shape of sample is maintained during drying.

In order to illustrate the effect of ignoring the reduction in exchange surface area, the mass flux $\left(\mathrm{kg} \cdot \mathrm{s}^{-1} \cdot \mathrm{m}^{-2}\right)$ was calculated according to the initial surface area, Eq. (2), and the actual reduced surface area, Eq. (3).

$$
\begin{aligned}
& q_{v}\left(A_{0}\right)=-\frac{d X}{d t} \times \frac{m_{s}}{A_{0}} \\
& q_{v}(A)=-\frac{d X}{d t} \times \frac{m_{s}}{A} .
\end{aligned}
$$

\subsubsection{Analysis of physical properties}

\subsubsection{Radial and longitudinal shrinkage}

The radial shrinkage coefficient (\%) and the longitudinal shrinkage coefficient (\%) were calculated from the following equations:

Radial shrinkage coefficient $=\left[\frac{d_{0}-d}{d_{0}}\right] \times 100$

Longitudinal shrinkage coefficient $=\left[\frac{\lambda_{0}-\lambda}{\lambda_{0}}\right] \times 100$

where " 0 " refers to the initial value $(t=0)$.

The shrinkage isotropicity is determined by the ratio of the reduction in diameter divided by the ratio of the reduction in height:

Shrinkage isotropicity $=\frac{\left(d_{0}-d\right) / d_{0}}{\left(\lambda_{0}-\lambda\right) / \lambda_{0}}$.

\subsubsection{Volume shrinkage}

The volume shrinkage $\left(S_{V}\right)$ is defined as the ratio between the volume obtained at a moisture content $X(\mathrm{~V})$ and the initial volume of the material $\left(V_{0}\right)$ :

$S_{V}=\frac{V}{V_{0}}$. 
The volume of the apple sample was calculated from its dimensions $(d, \lambda)$ measured during drying:

$V=\frac{1}{4}\left(\pi d^{2} \lambda\right)$.

\subsubsection{Diffusion coefficient}

According to Gekas and Lamberg [15], the diffusion coefficient in a volume changing system could be calculated using the following equation:

$\frac{D_{e f f}}{D_{e f f, r e f}}=\left(\frac{V}{V_{r e f}}\right)^{2 / d}$

where $D_{\text {eff }}$ is the effective diffusion coefficient $\left(\mathrm{m}^{2} / \mathrm{s}\right)$, $D_{\text {effiref }}$ is the reference effective diffusion coefficient $\left(\mathrm{m}^{2} / \mathrm{s}\right)$, $V$ is the sample volume at a moisture content $X\left(\mathrm{~m}^{3}\right)$, $V_{\text {ref }}$ is the reference volume (the initial volume) $\left(\mathrm{m}^{3}\right), d$ is a dimensionless exponent ranged between 1 and 3 .

The reference effective diffusion coefficient $\left(D_{\text {eff,ref }}\right)$ is the diffusivity obtained assuming negligible product shrinkage. It can be known from previous studies in the literature or from conducting another experiment.

The power exponent $(d)$ can be obtained from the relationship between the volume and height ratios of the samples during the drying process [15]:

$\frac{V(X)}{V_{0}}=\left(\frac{\lambda}{\lambda_{0}}\right)^{d}$

\subsubsection{Surface shrinkage}

The surface shrinkage $\left(S_{A}\right)$ was determined using the exchange surface area calculated at a moisture content $X$ $(A)$ divided by the initial exchange surface area $\left(A_{0}\right)$ of the apple sample:

$S_{A}=\frac{A}{A_{0}}$.

\subsubsection{Density}

The apparent density $\left(\rho_{a}\right)$ was calculated using the mass measurements of apple samples during drying and the corresponding volume values calculated from their dimension measurements.

The true density $\left(\rho_{t}\right)$ was determined using the following equation [16]:

$$
\rho_{t}=\frac{1}{\frac{x_{w}}{1000}+\frac{1-x_{w}}{1590}}
$$

where $x_{w}$ is the mass fraction of water in the apple sample (-).

\subsubsection{Porosity}

The porosity $(\varepsilon)$ of apple samples during drying was calculated using Eq. (13) [16]:

$\varepsilon=\frac{\rho_{t}-\rho_{a}}{\rho_{t}}$.

\section{Results and discussion}

\subsection{Mass Flux}

It can be noted from Fig. 1 the absence of a constant drying flux period despite of considering exchange surface area reduction. Similar behavior was reported by May and Perré [17] who related that to the high porosity of apple. In fact, the increase of the proportion of gaseous volume, during drying of apple, inhibits the capillary migration. As a result, the unsaturation of the exchange surface with free water enhances the starting of the falling rate stage.

\subsection{Radial and longitudinal shrinkage}

Fig. 2 shows some pictures of an apple sample according to radial and longitudinal directions at different times of drying. As seen in Fig. 3, the variations of the shrinkage in the radial and longitudinal directions versus the moisture content were not linear. The shrinkage coefficients present a clear anisotropy behavior: the shrinkage in the longitudinal direction was higher than in the radial direction. At the end of drying process, the isotropicity ratio was equal to 0.66 . These results are in agreement with those obtained by May and Perré [17] who observed the same behavior of shrinkage coefficients of apple samples with a shrinkage isotropicity of 0.56 . This behavior might be due to possible micromechanical effects that enhance the extension of shrinkage in many directions since the food material has an anisotropic structure [18].

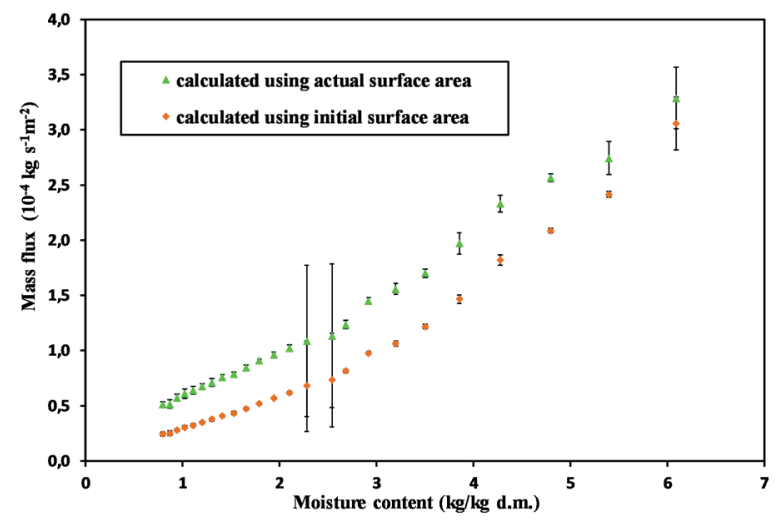

Fig. 1 Variation of mass flux with moisture content of apple samples 


\begin{tabular}{|c|c|c|c|c|c|c|c|c|c|}
\hline \multicolumn{10}{|l|}{$\begin{array}{l}\text { Radial } \\
\text { shrinkage }\end{array}$} \\
\hline \multicolumn{10}{|l|}{$\begin{array}{l}\text { Longitudinal } \\
\text { shrinkage }\end{array}$} \\
\hline $\begin{array}{l}\text { Drying time } \\
\text { (min) }\end{array}$ & 0 & 90 & 180 & 270 & 360 & 450 & 540 & 630 & 765 \\
\hline $\begin{array}{l}\text { Moisture } \\
\text { ratio }\end{array}$ & 1 & 0.494 & 0.289 & 0.175 & 0.105 & 0.037 & 0.026 & 0.022 & 0.019 \\
\hline
\end{tabular}

Fig. 2 Gallery of pictures of an apple sample according to radial and longitudinal directions as a function of drying time

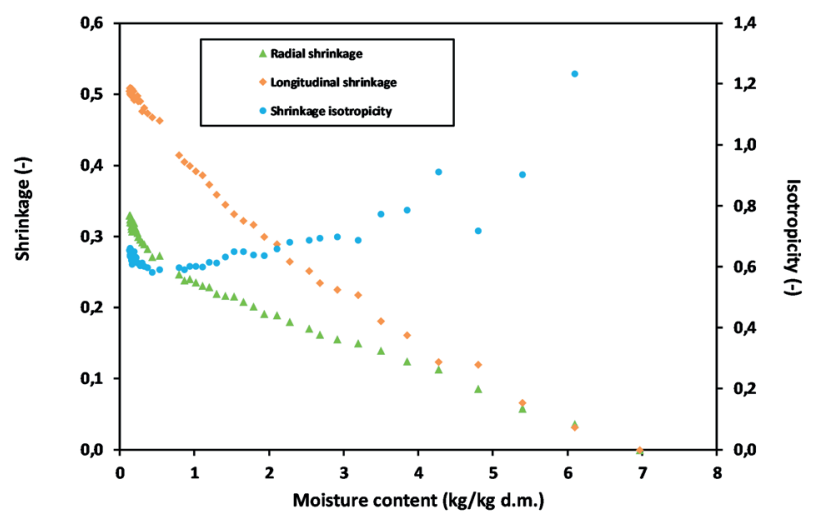

Fig. 3 Radial shrinkage, longitudinal shrinkage and shrinkage isotropicity versus moisture content of apples

\subsection{Volume shrinkage}

The variation of the volume shrinkage ratio $\left(S_{V}\right)$ of apple samples versus moisture content is given in Fig. 4. The volume change showed a linear correlation with moisture content, Eq. (14), with a correlation coefficient of 0.996:

$S_{V}=0.1118 X+0.224$.

Sjöholm and Gekas [18] also obtained a linear relationship between volume change and moisture content of Mutsu apple with $R^{2}=0.95$. Ratti [3] reported that for apples, potatoes and garlic, the relationship between shrinkage ratio and moisture content could be represented by two linear line segments which meet at a critical moisture content. Whereas for carrots and pears, the entire range of moisture contents was fitted by a linear relationship. Yan et al. [9] observed that the shrinkage behaviors of banana, pineapple and mango during air drying

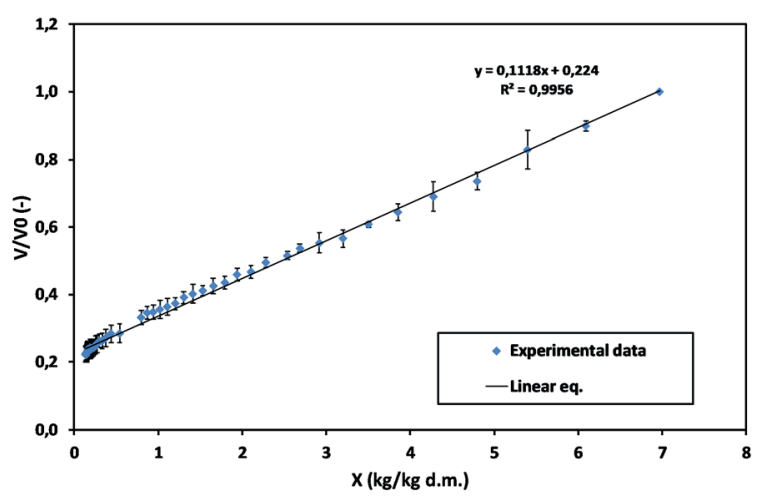

Fig. 4 Variation of volume shrinkage ratio of apple with moisture content.

(at $70{ }^{\circ} \mathrm{C}$ ) were well described by second order polynomials. A reduced degree of shrinkage was noted at the later stage of drying of these fruits.

At the end of drying process, the apple exhibited a shrinkage coefficient of $77.67 \%$. This could be resulted from the collapse phenomenon of cell walls of apple tissues associated to high amount of bound water in the cell walls of this apple variety as reported by Joardder et al. [14] for Red delicious apples. May and Perré [17] reported a shrinkage coefficient of $73 \%$ for air dried apples at $30{ }^{\circ} \mathrm{C}$. Lewicki and Jakubczyk [19] observed that the volumetric shrinkage of apples increases gradually from $49 \%$ to $58 \%$ with decrease in drying temperature from 80 to $50^{\circ} \mathrm{C}$. According to Witrowa-Rajchert and Rząca [1], the shrinkage of convectively dried apple was of $74 \%$, whereas the shrinkage of dried apples obtained by both microwave-convection and infrared-convection 
was lower by 11-12\% than that of convectively dried ones. Joardder et al. [14] observed a cell walls shrinkage of about $78.68 \%$ for Red delicious apples against $50 \%$ for Granny Smith variety. They explained this finding by the fact that the cell walls of Red delicious apples were stiffer, thicker and retained a higher amount of bound water than those of Granny Smith apples. The high density of cell walls of Red delicious apples was attributed to the amount of insoluble fibers in this variety.

Many studies have indicated that the shrinkage behavior is associated with various mechanisms such as pore pressure, mechanical strength of the matrix and glass transition [20].

The plot of volume ratio $\left(V / V_{0}\right)$ versus height ratio $\left(\lambda / \lambda_{0}\right)$ is given in Fig. 5. Equation (10) adequately described the relationship between volume and thickness ratios with a correlation coefficient of 0.995 and a standard error of 0.019 for an exponent of 2.138. Sjöholm and Gekas [18] reported an average $d$ value of $1.50 \pm 0.24$ for Mutsu apples and noted that this exponent did not be affected significantly neither by drying time nor by the size of apple samples.

The evolution of effective diffusion coefficient $\left(D_{\text {eff }}\right)$ versus moisture content during drying, could be obtained by introducing Eq. (14) into Eq. (9):

$D_{\text {eff }}=D_{\text {eff }, \text { ref }}(0.1118 X+0.224)^{2 / d}$.

$D_{\text {eff, ref }}$ can be calculated from a proposed mathematical model as follows [21]:

$$
\begin{aligned}
D_{\text {eff }, \text { ref }}= & \frac{1}{1+X} D_{0} \exp \left[-\frac{E_{0}}{R}\left(\frac{1}{T}-\frac{1}{T_{r e f}}\right)\right] \\
& +\frac{X}{1+X} D_{i} \exp \left[-\frac{E_{i}}{R}\left(\frac{1}{T}-\frac{1}{T_{r e f}}\right)\right]
\end{aligned}
$$

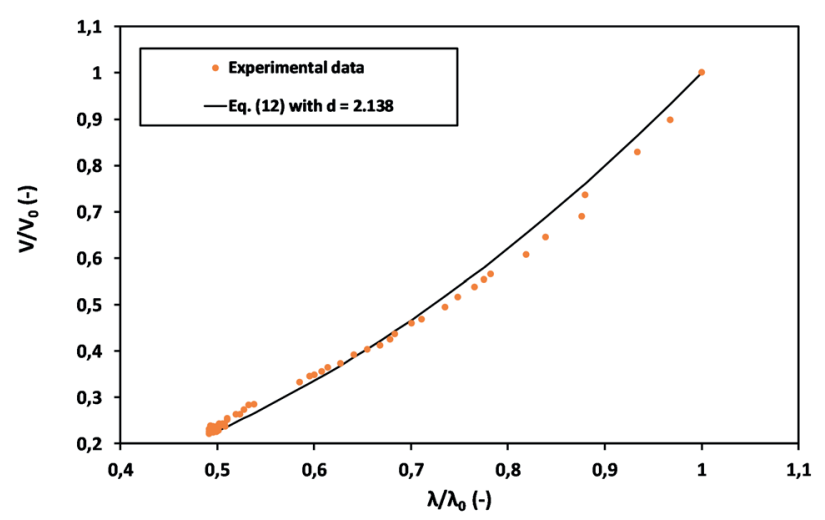

Fig. 5 Relationship between the volume ratio and the height ratio of apples during drying. where $T_{r e f}$ is the reference temperature, $D_{0}$ and $D_{i}$ are diffusivity at a temperature $T_{r e f}$ and moisture content $X=0$ and $X=\infty$, respectively, $E_{0}$ and $E_{i}$ are activation energy for diffusion in dry and wet material at $X=0$ and $X=\infty$, respectively, and $R$ is the ideal gas constant $(0.0083143 \mathrm{~kJ} / \mathrm{mol} \mathrm{K})$.

\subsection{Surface shrinkage}

Fig. 6 shows the evolution of the surface shrinkage ratio $\left(A / A_{0}\right)$ in respect of moisture content of apple samples. According to Kowalski and Mierzwa [22], a theoretical relation between the area ratio and the volume ratio, Eq. (17), could be determined since the area is of square dimension and the volume is of cube dimension:

$\frac{A}{A_{0}}=\left(\frac{V}{V_{0}}\right)^{2 / 3 a}$

where $a$ is an empirical coefficient introduced to consider possible anisotropic shrinkage and shriveling of the material surface.

As can be shown in Fig. 6, the experimental data of surface shrinkage were well correlated by Eq. (17) after substituting the volume ratio by its expression in function of water content, Eq. (14), with a correlation coefficient of 0.956 and a standard error of 0.052 for a coefficient value of 0.973 .

\subsection{Density}

Fig. 7 shows the evolution of the apparent density of apple in function of moisture content. The apparent density of apple decreased with removal of water during drying from an initial value of $743.323 \pm 17.59 \mathrm{~kg} / \mathrm{m}^{3}$ to a value of 476.586 $\pm 26.2 \mathrm{~kg} / \mathrm{m}^{3}$ at the end of drying. Similar trend was reported by Zogzas et al. [7] who related this behavior to the fact that apple exhibited a significant initial porosity which increased

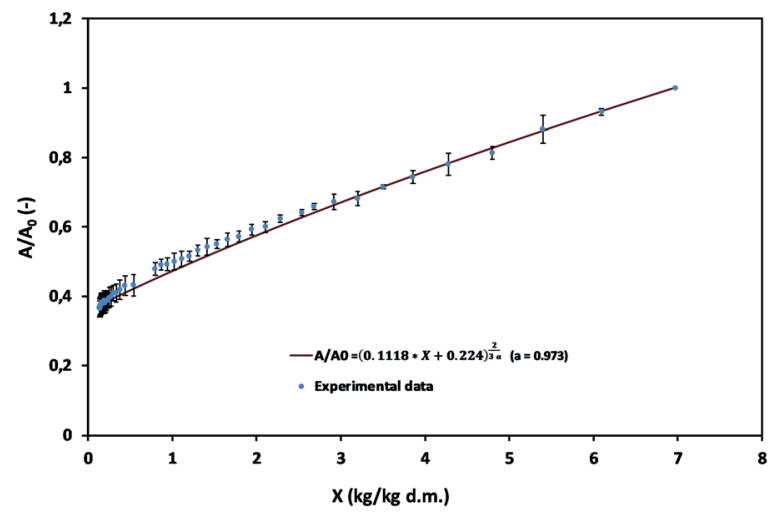

Fig. 6 Evolution of the surface shrinkage ratio in respect of moisture content of apple samples 


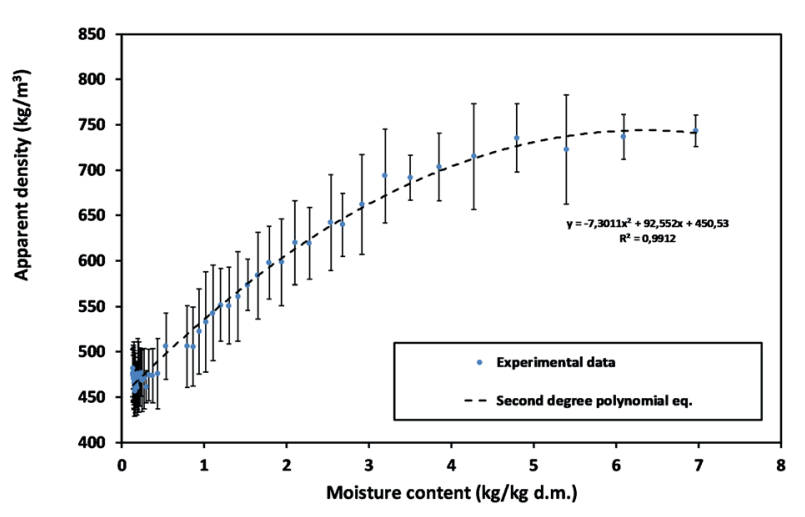

Fig. 7 Evolution of the apparent density of apple in function of moisture content

with decreasing moisture content. On the contrary, they observed that the apparent density of carrot and potato increased with decrease in moisture content. The experimental values of apparent density of apple correlated well with a second-degree polynomial curve $\left(R^{2}=0.991\right)$ :

$\rho_{\text {app }}=-7.301 X^{2}+92.552 X+450.53$.

As can be seen in Fig. 8, the true density of apple increased as drying proceeded from an initial value of 1048.853 $\pm 1.3 \mathrm{~kg} / \mathrm{m}^{3}$ to a final value of $1485.122 \pm 3.83 \mathrm{~kg} / \mathrm{m}^{3}$.

\subsection{Porosity}

Fig. 9 presents the evolution of the porosity of apple versus moisture content. Apple samples exhibited a high initial porosity of $29 \pm 0.016 \%$ which could be associated to their large cell volume [19]. During the drying process, the apple porosity increased until a final value of 68 $\pm 0.018 \%$. Similar result has been reported by May and Perré [17] who observed that apple porosity increased from 32 to $63 \%$ during air drying at $30{ }^{\circ} \mathrm{C}$. Zogzas et al. [7]

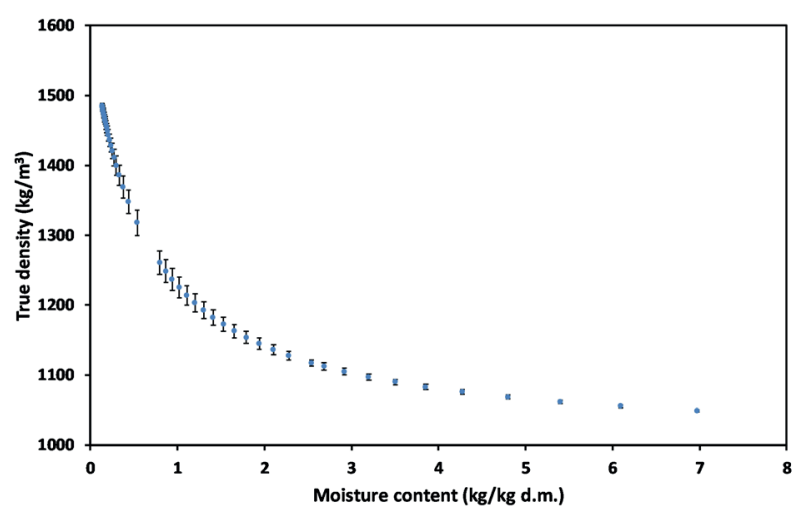

Fig. 8 Evolution of the true density of apple in function of moisture content

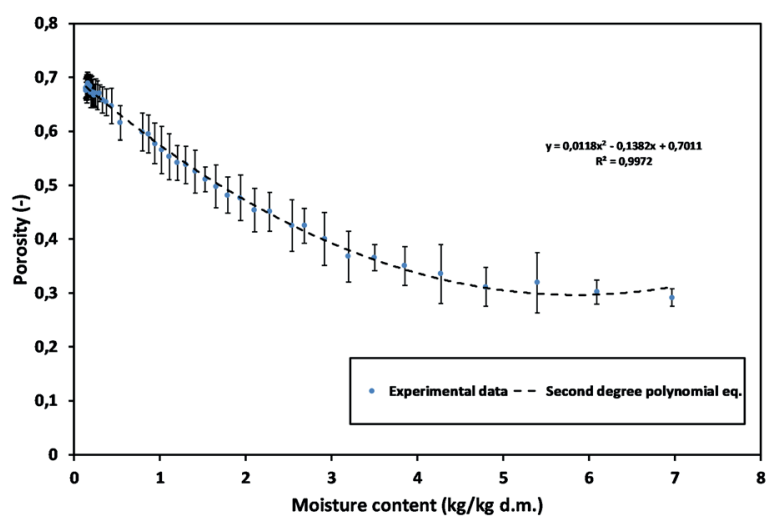

Fig. 9 Evolution of the porosity of apple versus moisture content

also found that the porosity of apple increased from 20 to $70 \%$ during air drying. On the contrary, carrots and potatoes were characterized by a low porosity $(<10 \%)$ during air drying. According to Singh et al. [11], the porosity changes during dehydration of apple samples were strongly affected by their initial porosity. As initial porosity value increases, the porosity values during dehydration increase. On the other hand, the porosity values increase with moisture removal as a result of increasing generated pressure. Joardder et al. [14] reported that a high porosity of dried apples could be related to their large cell dimensions which caused the loose packing of cells.

The variation of apple porosity in function of moisture content is illustrated by a second-degree polynomial curve, Eq. (19), with a correlation coefficient of 0.997:

$\varepsilon=0.012 X^{2}-0.138 X+0.701$.

In order to know whether the porosity changes were the result of a change of gaseous volume, a change of total volume or both simultaneously, the relationship between total volume reduction $\left(V_{0}-V\right)$ and mass reduction $\left(m_{0}-m\right)$ during drying process is presented in Fig. 10. The bisector could be obtained if the moisture loss is exactly converted to a total volume reduction.

At the beginning of the drying process (from a moisture content of $6.97 \pm 0.2$ until $5.4 \pm 0.237 \mathrm{~kg} / \mathrm{kg} \mathrm{d}$.m.), the relationship between volume reduction with mass reduction remained on the bisector until a mass reduction of 478.767 $\pm 4.793 \mathrm{mg}$ corresponding to a moisture content of 5.4 $\pm 0.237 \mathrm{~kg} / \mathrm{kg}$ d.m. During this period, the slight increase of the apple porosity could be explained by the decrease of the total volume resulting from the reduction of the cell size. From a moisture content of $5.4 \pm 0.237 \mathrm{~kg} / \mathrm{kg}$ d.m., the volume reduction became higher than the equivalent 


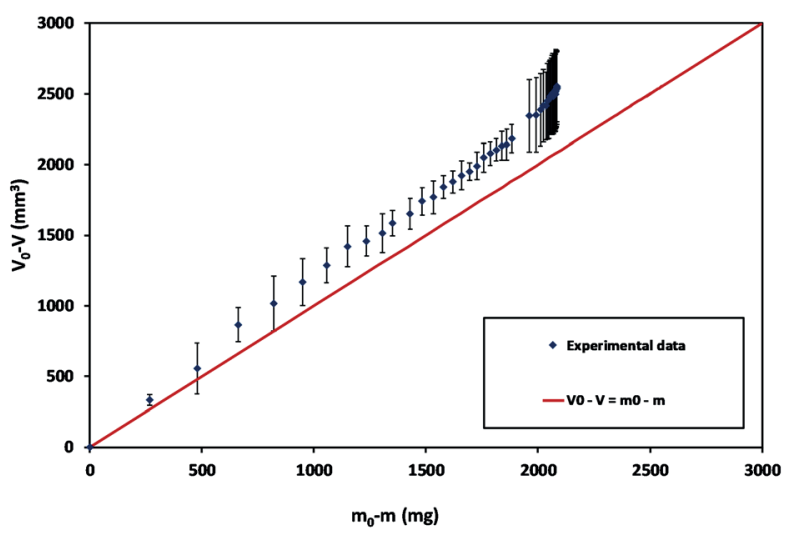

Fig. 10 Relationship between total volume reduction and mass reduction during drying of apple samples

volume of water loss. The relationship between $\left(V_{0}-V\right)$ and $\left(m_{0}-m\right)$ was described by the following equation with a correlation coefficient of 0.991 :

$V_{0}-V=1.195\left(m_{0}-m\right)$.

This may be explained by a simultaneous reduction of gaseous volume that allows a continuous increase of porosity. Similar behavior for apple samples was observed by May and Perré [17].

\section{Conclusion}

Through this work, the variation of the physical properties (shrinkage, density and porosity) of apples (Golden Delicious) during air drying was determined using the weight and dimensions (diameter, height) measurements monitored during drying. On the basis of this study, the following conclusions can be drawn:

- A constant drying flux period was not observed in spite of considering exchange surface area reduction.

- The radial and longitudinal shrinkage coefficients of Golden Delicious apples exhibited a marked anisotropy behavior with a final isotropicity ratio of 0.66 .

- A linear relationship was obtained between the volume shrinkage and the moisture content of apples $\left(R^{2}=0.996\right)$.

- The volume ratio was well correlated to the height ratio through an exponent value of $2.138\left(R^{2}=0.995\right)$.

- The effective diffusion coefficient was expressed in function of the relationship between the volume shrinkage and moisture content of apple samples.

- A theoretical relation between the surface ratio and the volume ratio was determined $\left(R^{2}=0.956\right)$
- During drying process, the apparent density of apples decreased with decrease in moisture content following a second-degree polynomial curve $\left(R^{2}=0.991\right)$, whereas the true density increased with removal of water.

- The porosity of apple samples increased from 29 to $68 \%$ during drying according to a second-degree polynomial curve $\left(R^{2}=0.997\right)$. At the beginning of the drying process, the porosity changes resulted from the reduction of the total volume. Then from a moisture content of $5.398 \mathrm{~kg} / \mathrm{kg}$ d.m., the porosity changes during drying were found to be a result of a loss of water and a simultaneous reduction of gaseous volume.

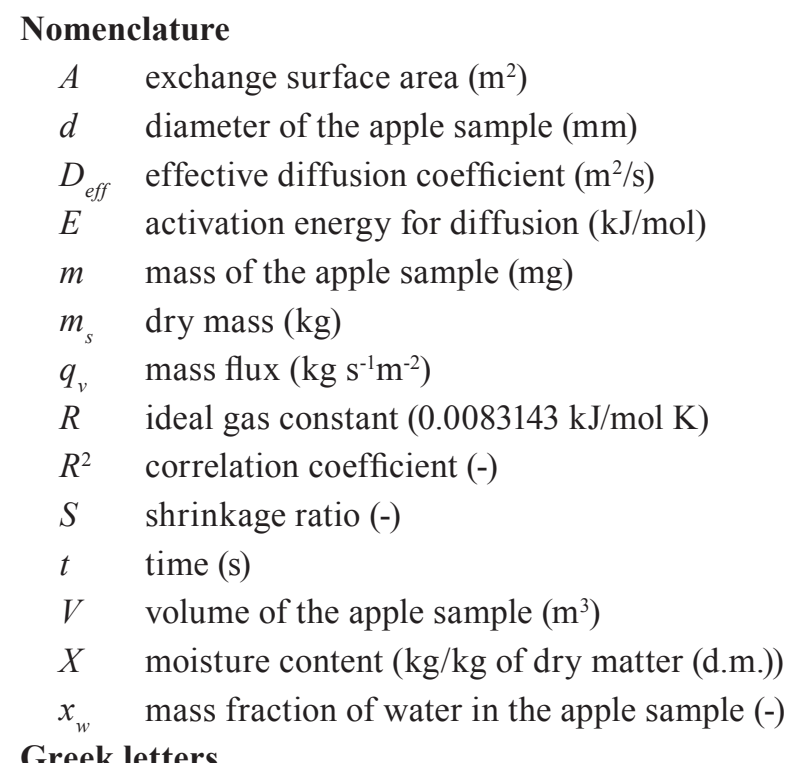

\section{Greek letters}

$\varepsilon \quad$ porosity (-)

$\lambda \quad$ height of the apple sample $(\mathrm{mm})$

$\rho$ density $\left(\mathrm{kg} / \mathrm{m}^{3}\right)$

\section{Subscripts}

$\begin{array}{ll}0 & \text { initial } \\ a & \text { apparent } \\ A & \text { surface } \\ r e f & \text { reference } \\ t & \text { true } \\ V & \text { volume }\end{array}$

\section{Superscripts}

$a$ empirical coefficient in the relation between the area and the volume ratios (-) $d$ power exponent in the relation between the volume and height ratios (-) 


\section{References}

[1] Witrowa-Rajchert, D., Rząca, M. "Effect of Drying Method on the Microstructure and Physical Properties of Dried Apples", Drying Technology, 27(7-8), pp. 903-909, 2009. https://doi.org/10.1080/07373930903017376

[2] Pakowski, Z., Adamski, R. "Formation of Underpressure in an Apple Cylinder during Convective Drying", Drying Technology, 30(11-12), pp. 1238-1246, 2012.

https://doi.org/10.1080/07373937.2012.698440

[3] Ratti, C. "Shrinkage during drying of foodstuffs", Journal of Food Engineering, 23(1), pp. 91-105, 1994. https://doi.org/10.1016/0260-8774(94)90125-2

[4] Funebo, T., Ahrné, L., Kidman, S., Langton, M., Skjöldebrand, C. "Microwave heat treatment of apple before air dehydration effects on physical properties and microstructure", Journal of Food Engineering, 46(3), pp. 173-182, 2000. https://doi.org/10.1016/S0260-8774(00)00080-7

[5] Krokida, M. K., Kiranoudis, C. T., Maroulis, Z. B., MarinosKouris, D. "Drying Related Propertis of Apple", Drying Technology, 18(6), pp. 1251-1267, 2000. https://doi.org/10.1080/07373930008917775

[6] Madamba, P. S., Driscoll, R. H., Buckle, K. A. "Shrinkage, density and porosity of garlic during drying", Journal of Food Engineering, 23(3), pp. 309-319, 1994. https://doi.org/10.1016/0260-8774(94)90056-6

[7] Zogzas, N. P., Maroulis, Z. B., Marinous-Kouris, D. "Densities, shrinkage and porosity of some vegetables during a drying", Drying Technology, 12(7), pp. 1616-1653, 1994. https://doi.org/10.1080/07373939408962191

[8] Saravacos, G. D. "Effect of the Drying Method on the Water Sorption of Dehydrated Apple and Potato", Journal of Food Science, 32(1), pp. 81-84, 1967. https://doi.org/10.1111/j.1365-2621.1967.tb01963.x

[9] Yan, Z., Sousa-Gallagher, M. J., Oliveira, F. A. R. "Shrinkage and porosity of banana, pineapple and mango slices during air-drying", Journal of Food Engineering, 84(3), pp. 430-440, 2008. https://doi.org/10.1016/j.jfoodeng.2007.06.004

[10] Madiouli, J., Sghaier, J., Lecomte, D., Sammouda, H. "Determination of porosity change from shrinkage curves during drying of food material", Food and Bioproducts Processing, 90(1), pp. 43-51, 2012. https://doi.org/10.1016/j.fbp.2010.12.002

[11] Singh, F., Katiyar, V. K., Singh, B. P. "Mathematical modeling to study influence of porosity on apple and potato during dehydration", Journal of Food Science and Technology, 52(9), pp. 5442-5455, 2015. https://doi.org/10.1007/s13197-014-1647-5
[12] Wang, D., Martynenko, A. "Estimation of total, open-, and closedpore porosity of apple slices during drying", Drying Technology, 34(8), pp. 892-899, 2016. https://doi.org/10.1080/07373937.2015.1084632

[13] Qiu, J., Khalloufi, S., Martynenko, A., Van Dalen, G., Schutyser, M., Almeida-Rivera, C. "Porosity, Bulk Density, and Volume Reduction During Drying: Review of Measurement Methods and Coefficient Determinations", Drying Technology, 33(14), pp. 1681-1699, 2015. https://doi.org/10.1080/07373937.2015.1036289

[14] Joardder, M. U. H., Brown, R. J., Kumar, C., Karim, M. A. "Effect of Cell Wall Properties on Porosity and Shrinkage of Dried Apple", International Journal of Food Properties, 18(10), pp. 2327-2337, 2015.

https://doi.org/10.1080/10942912.2014.980945

[15] Gekas, V., Lamberg, I. "Determination of diffusion coefficients in volume-changing systems-Application in the case of potato drying", Journal of Food Engineering, 14(4), pp. 317-326, 1991. https://doi.org/10.1016/0260-8774(91)90021-J

[16] Andrés, A., Bilbao, C., Fito, P. "Drying kinetics of apple cylinders under combined hot air-microwave dehydration", Journal of Food Engineering, 63(1), pp. 71-78, 2004. https://doi.org/10.1016/S0260-8774(03)00284-X

[17] May, B. K., Perré, P. "The importance of considering exchange surface area reduction to exhibit a constant drying flux period in foodstuffs", Journal of Food Engineering, 54(4), pp. 271-282, 2002. https://doi.org/10.1016/S0260-8774(01)00213-8

[18] Sjöholm, I., Gekas, V. "Apple shrinkage upon drying", Journal of Food Engineering, 25(1), pp. 123-130, 1995. https://doi.org/10.1016/0260-8774(94)00001-P

[19] Lewicki, P. P., Jakubczyk, E. "Effect of hot air temperature on mechanical properties of dried apples", Journal of Food Engineering, 64(3), pp. 307-314, 2004. https://doi.org/10.1016/j.jfoodeng.2003.10.014

[20] Kurozawa, L. E., Hubinger, M. D., Park, K. J. "Glass transition phenomenon on shrinkage of papaya during convective drying", Journal of Food Engineering, 108(1), pp. 43-50, 2012. https://doi.org/10.1016/j.jfoodeng.2011.07.033

[21] Mujumdar, A. S. "Handbook of Industrial Drying", 3rd ed., CRC Press, Boca Raton, FL, USA, 2006.

[22] Kowalski, S. J., Mierzwa, D. "Numerical analysis of drying kinetics for shrinkable products such as fruits and vegetables", Journal of Food Engineering, 114(4), pp. 522-529, 2013. https://doi.org/10.1016/j.jfoodeng.2012.08.037 